\title{
CITA-CITA HARMONIS MASYARAKAT KERINCI DALAM KUNAUNG KERINCI
}

\section{HARMONIOUS DREAMS OF THE KERINCI COMMUNITY IN KUINAUNG KERINCI}

\author{
Mahawitra Jayawardana; Silvia Rosa; Khairil Anwar
}

Program Studi Magister Ilmu Sastra

Program Pascasarjana Fakultas Ilmu Budaya Universitas Andalas

Jalan Limau Manis, Pauh, Kota Padang, Sumatra Barat, Indonesia

mahawitra@gmail.com

(Naskah diterima tangga 10 Juni 2021, direvisi terakhir tanggal 23 September 2021, dan disetujui tanggal 2 Desember 2021)

DOI: $\underline{\text { https:/ / doi.org/10.26499/wdprw.v49i2.849 }}$

\begin{abstract}
This article aims to reveal the meaning behind the expelled events contained in the Kunaung Putri Bungsu Rindu Sekian and the Kunaung Si Kamba Paya. The semiological theory of Roland Barthes is applied to reveal the symbolic foundation that wraps the discourse of these two ancients. This research is a qualitative research with descriptive method by analyzing the data in the form of words, sentences, paragraphs and even the discourse contained in the kunaung text. The results of the analysis show that kunaung becomes a symbolic code as a curtain of reason to silence the collective tragedy of the past so that it does not become a collective disease in the Kerinci community. The two kunaung have become the harmonious ideals of the ancestors of the Kerinci people for life in the future. Kunaung acts as a tool to voice these ideals.
\end{abstract}

Keywords: Kerinci; kunaung; terusir; semiologi

\begin{abstract}
Abstrak
Artikel ini bertujuan untuk mengungkap makna di balik peristiwa terusir yang terdapat dalam kunaung Putri Bungsu Rindu Sekian dan kunaung Si Kamba Paya.Teori semiologi Roland Barthes diterapkan untuk mengungkap tumpuan simbol yang membungkus wacana dalam kedua kunaung ini. Penelitian ini ialah penelitian kualitatif dengan metode deskriptif dengan menganalisis data berupa kata, kalimat, paragraf, bahkan wacana yang terdapat pada teks kunaung. Hasil analisis menunjukkan bahwa kunaung menjadi kode simbolik yang bermakna sebagai tirai nalar untuk membungkam tragedi kolektif masa lalu supaya tidak menjadi luka kolektif dalam masyarakat Kerinci. Kedua kunaung itu menjadi cita-cita harmonis nenek moyang orang Kerinci untuk kehidupan di masa depan. Kunaung berperan sebagai alat untuk menyuarakan cita-cita tersebut.
\end{abstract}

Kata-kata kunci: Kerinci; kunaung; terusir; semiologi

\section{Pendahuluan}

Kunaung Kerinci merupakan sastra lisan Kerinci yang mengandung gagasan-gagasan, konsep, atau pun nilai-nilai yang ada di balik teksnya. Kunaungtumbuh dan berkembang di tengah masyarakat Kerinci dari satu generasi ke generasi selanjutnya. Kunaung menjadi bagian penting dalam kolektif masyarakat Kerinci.Namun, dalam kunaung terdapat peristiwa tokoh-tokoh yang terusir. Hal 
inilah yang menarik untuk didedah dengan perspektif Barthes. Mengapa dalam kunaung Kerinci persoalan seperti itu ada. Apa relevansinya dengan masyarakat Kerinci?

Kunaung merupakan sastra lisan Kerinci yang berbentuk prosa (Karimi, 1968).Sastra lisan Kerinci jenis ini memiliki ciri khusus. Udin (1983:13) mengatakanbahwa kunaung adalah bentuk cerita rakyat yang dilagukan. Hal itu yang menjadi ciri khusus dari kunaung.Kunaung tidak diceritakan begitu saja dari satu orang ke orang lain, tetapi melalui beberapa proses khusus. Kunaung diturunkan secara lisan dari satu generasi ke generasi selanjutnya melalui prosesi-prosesi tertentu, seperti menyiapkan hulu nasi, telur ayam rebus, yang diadakan di tempat tertentu sehingga dapat menyebabkan pendengar kunaung terhipnotis, seperti menangis atau pun mengamuk. Hal tersebut menunjukkan bahwa kunaung memiliki posisi penting dalam masyarakat Kerinci. Kunaung memiliki konsep yang sangat penting di balik makna yang selama ini disepakati oleh masyarakat.

Kunaung yang ada di Kerinci, antara lain, kunaung Putri Bungsu Rindu Sekian dan kunaungSi Kamba Paya. Kedua kunaung ini berkisah mengenai putri raja yang terusir dari kampungnya sendiri. Kunaung Putri Bungsu Sekian terdapat persoalan terusirnya putri raja yang mewarisi kekuasaan dan harta yang dilakukan oleh paman kandungnya.Terusirnya putri tersebut dilakukan setelah kedua orang tuanya meninggal.Kunaung Si Kamba Paya berkisah mengenai seorang putri raja yang terusir akibat memiliki mainan yang lebih baik dibandingkan dengan milik saudara sepupunya.Terusirnya putri ini dilakukan oleh bibi kandungnya sendiri. Peristiwa terusir dalam kedua kunaung menjadi suatu persoalan yang tematik karena memiliki kesamaan persoalan. Sebab bermula dari peristiwa terusir inilah cerita dalam kedua kunaung ini dapat terbangun sehingga menjadikan kunaung hidup di tengah masyarakat Kerinci.

Halitu menimbulkan pertanyaan, apa yang menyebabkan peristiwa mengemuka dalam kedua kunaung ini? Apakah peristiwa terusirhanya sebagai bumbu cerita agar memberikan kesan yang mendalam bagi pendengarnya atau justru terdapat hal lain yang berusaha untuk ditutupi melalui peristiwa terusir tersebut?Untuk itu, tulisan ini berupaya untuk mengungkap mengapa peristiwa terusir ada dalam kunaung Putri Bungsu Rindu Sekian dan kunaung Si Kamba Paya.

Kunaung sebagai karya sastra merupakan situs tanda yang menyembunyikan banyak hal, baik itu gagasan-gagasan, nilai, maupun konsep-konsep yang dimiliki oleh masyarakat pemilik karya sastra lisan tersebut. Oleh sebab itu, pengungkapan makna yang ada di balik teks kunaung dilakukan melalui pisau analisis semiologi Barthes.

Sebagai karya sastra, kunaung merupakan sekumpulan tanda dan gagasan nilai yang terkandung dalam masyarakat. Rosa (2015:5) mengatakan bahwa teks sastra ialah wujud perlambangan yang secara potensial dapat menampilkan gambaran objek, suasana, gagasan, nilai ideologis. Teks sastra merupakan sistem tanda.

Sebagai sebuah sistem tanda, teks sastra secara asosiatif berhubungan dengan sesuatu di luar wujud kongkretnya sehingga teks sastra disebut sebagai sistem semiotik. Begitujuga dengan kunaung Putri Bungsu Rindu Sekian dan kunaung Si Kamba Paya yang merupakan sebuah sistem tanda.Melaluirelasi pertandaan yang terdapat di dalamnya, hal-hal yang kontradiktif dialihkan ke tataran simbolis dengan cara yang apik dan rapi. Realitas yang ada sebelumnya dikemas dengan rapi dan berterima logika manusia. Pada tahap 
inilah kunaung menjadi seperti tirai nalar yang menentukan cara manusia memandang dan menafsirkan kehidupan sehari-hari. Sehubungan dengan itu, perspektif semiologi Barthes dipakai untuk membedah kunaung untuk menemukan makna apa yang terkandung dalam rangka membongkar tirai nalar tersebut.

Semiologi menurut Barthes merupakan ilmu mengenai bentuk karena ia mempelajari tanda secara terpisah dari kandungannya (Barthes, 1983: 156). Barthes mengatakan bahwa dalam semiologi terdapat dua jenis pemaknaan, yaitu sistem denotasi dan konotasi. Denotasi merupakan sistem signifikansi tingkat pertama yang terdiri atas rantai penanda dan petanda, yakni hubungan materialitas antara penanda dan konsep abstrak dibaliknya. Sementara itu, konotasi merupakan sistem pertandaan tingkat kedua (Piliang, 2019: 144). Oleh karena itu, ia menganggap bahwa pemaknaan terjadi dalam dua tahap, yaitu tanda (penanda dan petanda) pada tahap pertama atau denotasi bergabung sehingga dapat membentuk penanda pada tahap kedua. Pada tahap berikutnya ialah penanda dan petanda yang telah bergabung tersebut dapat membentuk petanda baru yang disebut dengan perluasan makna. Barthes menganggap bahwa makna konotatif dianggap penting. Bahkan, pemaknaan pada tatanan ketiga jauh lebih penting dan ideologis. Pada tataran inilah makna ideologi itu bersemayam.

Barthes menyodorkan pendekatan baru dalam kritik sastra yang disebutnya nouvelle critique (kritik sastra baru), yaitu tempat kritik bagi pembaca. Pembaca bagi Barthes adalah subyek yang memproduksi makna, sedangkan teks menjadi terbuka terhadap segala kemungkinan. Pembaca berhadapan dengan pluralitas signifikasi. Bagi Barthes, tafsir tunggal menjadi sebuah cara represif yang tidak produktif (Kurniawan, 2001: 94).
Cara kerja Barthes ialah dengan merekontruksi ulang teks yang akan dianalisis. Dengan demikian, akan ditemukan makna lain yang selama ini bersemanyam di balik tataran makna pertama.

Proses pemaknaan memerlukan atensi yang lebih luas atas dimensi makna dan pluralitas teks. Barthes (1974: 13) memilahmilah penanda pada wacana teks ke dalam fragmen ringkas dan beruntun yang disebut leksia. Leksia menjadi sebuah acuan dalam menemukan makna karena menurut Barthes, masing-masing leksia memiliki beberapa kemungkinan makna. Setelah pemilahan teks dilakukan, leksia dikelompokkan ke dalam lima kode, yaitu, kode hermeneutik, kode semik, kode proaeretik, kode simbolik, dan kode kultural. Penelitian ini berupaya mencari tahu makna di balik konsep atau gagasan yang terdapat dalam kunaung Putri Bungsu Rindu Sekian dan kunaung Si Kamba Paya melalui semiologi Roland Barthes.

Beberapa penelitian terkait kunaung Kerinci yang pernah dilakukan, antara lain, Maiza (2020) dalam penelitiannya yang berjudul Autonomy Of Kerinci's Kunun Toward Character Education In Primary Schools In Sungai Penuh City. Penelitian ini menunjukkan bahwa kunaung mengandung banyak nilai karakter yang dapat digunakan sebagai media pembelajaran. Namun, penerapan kunaung sebagai media pembelajaran belum optimal disebabkan banyak kendala. Jaya (2019)dalam artikelnya berjudul The Value of Religious Education in Kerinci Kunun Text. Penelitian ini menunjukkan bahwa kunaung mengandung nilai-nilai pendidikan yang mengarah kepada pendidikan karakter anak.

Selain itu, terdapat penelitian Efrison (2017) yang berjudul Analisis Cerita Tupai Janjang: Teori Fungsi William R Bascom. Efrison (2017: 10) mengemukakan bahwa kunaung Tupai Janjang menjadi sistem proyeksi anganangan kolektif masyarakat Kerinci. Kunaung 
itu menjadi media yang mengesahkan pranata-pranata lembaga adat, alat pendidikan, dan alat untuk mengontrol masyarakat. Sementara itu, Nazurty (2016: 72) dalam artikelnya berjudul Semiotic Review of Verbal Literature of Riwok Kerinci menjelaskan bahwa riwok sebagai sastra lisan Kerinci merupakan gambaran batas-batas adat, kepemimpinan dalam wilayah adat, norma adat, peran, perilaku, dan tugas pemimpin adat dalam budaya Kerinci.

Penelitian sastra lisan melalui pendekatan semiology, pernah dilakukan oleh Rosa (2019) tentang Tambo Minangkabau dengan judul Deceptive Strategies in Literature: The Meaning of Folded Story. Dua episode cerita dalam Tambo Minangkabau menunjukkan bahwa Tambo menjadi alat untuk menutupi tragedi masa lalu dalam sejarah masyarakat Minangkabau agar tidak diterima dengan jelas oleh generasi selanjutnya. Tambo sebagai karya sastra menjadi kode simbolik yang menjadi alat mediasi ingatan kolektif dari peristiwa tragis (Rosa, 2019: 12-13).

Kalelioğlu dan Günay (2018) meneliti sastra lisan Turki dalam artikelnya yang berjudul Analysis of Duha Koca Oglu Deli Dumrul Narrative Within The Framework of Literary Semiotics. Kalelioğlu dan Günay (2018: 254) menyimpulkan bahwa kisah-kisah Dede Korkut dalam sastra lisan Turki mengungkap karakteristik sosial masyarakat Turki. Kisah-kisah ini menampilkan keimanan orang Turki kepada Allah, sentimen moral, nilai-nilai, semangat, dan pandangan mereka tentang konsep keluarga dan cinta. Kedua penelitian tersebut adalah upaya untuk mengungkapkan makna-makna yang ada dalam sastra lisan.

Penelitian ini berbeda dengan penelitian sebelumnyayang . Penelitian ini ialah upaya untuk mengungkap makna yang ada di balik peristiwa terusir dalam kunaung Putri Bungsu Rindu Sekian dan kunaung Si Kamba Paya menggunakan pendekatan semiologi Roland Barthes.

\section{Metode}

Jenis penelitian ini ialah kualitatif dengan metode deskriptif dalam menganalisis teks kunaung Putri Bungsu Rindu Sekian dan kunaung Si Kamba Paya. Data penelitian ini ialah transkripsi kunaung Putri Bungsu Rindu Sekian dan kunaung Si Kamba Paya (Udin, 1983). Analisis data dilakukan dengan mengelompokkan unit-unit leksia yang terdapat pada kata, kalimat, paragraph, bahkan wacana. Kemudian, data diklasifikasikan ke dalam lima kode yang dikembangkan oleh Barthes, selanjutnya diintrepatsikan maknanya yang terkait dengan peristiwa terusir. Pada tahapan akhir dibuat simpulan.

\section{Hasil dan Pembahasan}

\subsection{Hasil Penelitian}

Kunaung Putri Rindu Sekian berkisah tentang seorang raja bernama Datuk Agung dan istrinya bernama Putri Bungsu yang telah lama menantikan hadirnya seorang anak. Raja dan istrinya telah melakukan berbagai upaya untuk dapat memiliki keturunan; mereka selalu berdoa dan berusaha setiap hari, tetapi belum berhasil.

Ketiadaan keturunan itu membuat mereka berpisah. Sang Raja harus meninggalkan rumah beserta segala kekuasaan yang ia miliki untuk mencari perempuan yang dapat menghasilkan keturunan. Namun, sang Raja tidak menemukan perempuan yang mampu menandingi kecantikan dan kebaikan istrinya. Setelah merenung, mereka berdua sepakat tidak dapat hidup jika tidak bersama sehingga mereka pun rujuk.

Setelah mereka rujuk si istri pun hamil dan kemudian melahirkan seorang anak perempuan yang dinamakan seperti ibunya, yaitu Putri Bungsu. Kegembiraan mereka tidak berlangsung lama karena setelah si istri 
melahirkan, raja meninggal dunia. Selang beberapa lama kemudian, akibat proses melahirkan yang susah si istri pun meninggal. Tinggallah anaknya sendiri. Oleh sebab itu, saudara si istri berunding, siapakah yang akan merawat Putri tersebut. Namun, saudara tertua si istri atau paman putri mengusulkan agar Putri harus dibuang karena membawa sial yang menyebabkan raja dan istrinya meninggal dunia. Pamanpaman putri yang lain tidak ada yang berani membantah. Akhirnya, Putri pun terusir dari kampungnya sendiri. Hal itu sesungguhnya ialah upaya dari sang paman untuk menguasai harta dan kekuasaan yang diwariskan kepada Putri. Sekian lama berselang, Putri Bungsu dapat kembali ke kampung halaman karena diselamatkan oleh binatang dan hewan yang mengakui bahwa ia adalah putri Datuk Agung, raja yang telah meninggal.

Kunaung Si Kamba Paya berkisah tentang seorang putri raja yang dititipkan oleh ibunya kepada bibinya selama mereka pergi ke hutan.Putri raja pun bermain dengan saudara sepupunya. Namun, putri raja memiliki mainan yang lebih bagus sehingga membuat sepupunya iri dan menangis karena ingin memiliki mainan yang sama. Mengetahui hal tersebut bibinya mengejar dan ingin memukul Putri. Bibinya juga mengatakan jangan pernah pulang ke kampung tersebut. Putri pun terusir dari kampungnya sendiri. Ia lari sampai ke hutan dan tidak berani kembali.

Ketika Putri berada di hutan, ia mencari bunga kembang payung. Bunga ituialah bunga yang indah dan sakti. Setelah sekian lama berjalan, ia menemukan sebuah rumah yang dihuni oleh seorang nenek. Nenek tersebut mengatakan bahwa ia memiliki bunga kembang payung. Namun, untuk bisa mendapatkan bunga tersebut, Putri harus menikah dengan cucu nenek ketika sudah dewasa. Setelah dewasa dan menikah, Putri pun kembali ke kampung menggunakan bunga kembang payung. Rakyat pun tahu jika ia adalah putri raja yang telah lama hilang. Pada akhirnya putri dan suaminya menjadi pemimpin di kampung tersebut.

Pengungkapan makna yang berada di balik peristiwaterusir dalam kedua kunaung ini dilakukan dengan menentukan leksia untuk dianalisis. Analisis leksia yang dilakukan pada kedua teks kunaung meliputi kata, kalimat, paragraf, bahkan wacana untuk menemukan satuan-satuan makna. Langkah ini serupa dengan yang dilakukan oleh Barthes saat mendedah novel Sarrasine.

Leksia yang terdapat pada teks kunaung Putri Bungsu Rindu Sekian berjumlah 66, sedangkan pada teks kunaung Si Kamba Paya sebanyak 45 buah leksia. Leksia pada kedua kunaung itu menunjukkan memiliki kesamaan peristiwa besar yang mengemuka, yaitu terusirnya tokoh perempuan yang mewarisi sko tinggi (pusaka tinggi). Pengusiran kedua putri raja itu dilakukan oleh anggota keluarganya yang lain.

Pada kunaung Putri Bungsu Rindu Sekian, sang putri diusir oleh pamannya sendiri dengan alasan sebagai anak yang membawa celaka, sedangkan pada kunaung Si Kamba Paya sang putri diusir oleh bibinya karena memiliki mainan yang lebih bagus dibandingkan milik anaknya. Analisis leksia semakin mengerucutkan pada anggapan awal dari persoalan yang ada di kedua kunaung, yakni mengenai upaya anggota keluarga yang lain untuk menyingkirkan pewaris sko oleh orang yang akan menjadi pewaris apabila pewaris yang sah meninggal atau tidak diketahui keberadaannya.

\subsubsection{Kode-kode dalam Kunaung Putri Bungsu Rindu Sekian dan Kunaung Si Kamba Paya}

Leksia yang telah ditentukan sebelumnya akan membimbing kita untuk mengupas dan memahami kode-kode yang ada di dalam 
kunaung. Barthes mengatakan bahwa kode tersebut ialah kode hermeneutik, kode semik, kode simbolik, dan kode kultural. Leksia yang tergolong ke dalam lima kode tersebut akan memandu kita untuk mengupas teks secara mendalam untuk menemukan makna apa yang sebenarnya tersembunyi di balik teks kunaung.

Tabel 1 menampilkan leksia dalam kunaung Putri Bungsu Rindu Sekian dan kodekode yang mengikutinya.

\section{Tabel 1}

Kode dalam kunaung Putri Bungsu Rindu Sekian

\begin{tabular}{|c|c|c|c|}
\hline Kode & $\begin{array}{c}\text { No. } \\
\text { Leksia }\end{array}$ & Unit Leksia & Makna \\
\hline \multirow{8}{*}{$\begin{array}{l}\text { Herme } \\
\text { neutik }\end{array}$} & 1 & $\begin{array}{l}\text { Perempuan } \\
\text { bernama } \\
\text { Putri } \\
\text { Bungsu }\end{array}$ & $\begin{array}{l}\text { Pewaris } \\
\text { pusaka tinggi }\end{array}$ \\
\hline & 9 & $\begin{array}{l}\text { Datuk } \\
\text { Agung } \\
\text { terpilih } \\
\text { menjadi raja }\end{array}$ & $\begin{array}{l}\text { Raja baru } \\
\text { memimpin }\end{array}$ \\
\hline & 11 & $\begin{array}{l}\text { Datuk } \\
\text { Agung dan } \\
\text { istrinya } \\
\text { belum } \\
\text { memiliki } \\
\text { anak }\end{array}$ & $\begin{array}{l}\text { Permasalahan } \\
\text { dalam } \\
\text { pernikahan }\end{array}$ \\
\hline & 13 & $\begin{array}{l}\text { Datuk } \\
\text { Agung } \\
\text { mengajak } \\
\text { istrinya } \\
\text { berpisah }\end{array}$ & $\begin{array}{l}\text { Perceraian } \\
\text { raja dan } \\
\text { istrinya }\end{array}$ \\
\hline & 15 & $\begin{array}{l}\text { Putri } \\
\text { Bungsu } \\
\text { tidak mau } \\
\text { bercerai }\end{array}$ & Penolakan \\
\hline & 17 & $\begin{array}{l}\text { Panjang } \\
\text { rambut } \\
\text { Putri } \\
\text { Bungsu }\end{array}$ & $\begin{array}{l}\text { Kekuasaan } \\
\text { yang dimiliki } \\
\text { perempuan } \\
\text { Kerinci }\end{array}$ \\
\hline & 22 & $\begin{array}{l}\text { Datuk } \\
\text { Agung pergi } \\
\text { membuang } \\
\text { diri }\end{array}$ & $\begin{array}{l}\text { Raja pergi } \\
\text { tanpa } \\
\text { membawa } \\
\text { apa-apa }\end{array}$ \\
\hline & 32 & $\begin{array}{l}\text { Datuk } \\
\text { Agung } \\
\text { disuruh } \\
\text { kembali }\end{array}$ & $\begin{array}{l}\text { Rujuknya raja } \\
\text { dan mantan } \\
\text { istrinya }\end{array}$ \\
\hline
\end{tabular}

\begin{tabular}{|c|c|c|}
\hline & $\begin{array}{l}\text { pada Putri } \\
\text { Bungsu } \\
\text { dalam } \\
\text { mimpi }\end{array}$ & \\
\hline 43 & $\begin{array}{l}\text { Putri } \\
\text { Bungsu } \\
\text { Rindu } \\
\text { Sekian lahir } \\
\end{array}$ & $\begin{array}{l}\text { Pewaris harta } \\
\text { lahir }\end{array}$ \\
\hline 50 & $\begin{array}{l}\text { Putri } \\
\text { Bungsu } \\
\text { akan } \\
\text { dibuang } \\
\text { oleh } \\
\text { pamannya }\end{array}$ & $\begin{array}{l}\text { Ahli waris } \\
\text { tersingkir }\end{array}$ \\
\hline 55 & $\begin{array}{l}\text { Kerbau } \\
\text { menemukan } \\
\text { Putri } \\
\text { Bungsu }\end{array}$ & Bantuan \\
\hline 60 & $\begin{array}{l}\text { Putri } \\
\text { Bungsu } \\
\text { dibuang lagi } \\
\text { ke rimba } \\
\end{array}$ & $\begin{array}{l}\text { Upaya untuk } \\
\text { menyingkirka } \\
\mathrm{n} \text { pewaris } \\
\text { yang sah }\end{array}$ \\
\hline 64 & $\begin{array}{l}\text { Putri } \\
\text { Bungsu } \\
\text { mendapatka } \\
\mathrm{n} \text { bantuan } \\
\text { dari merpati }\end{array}$ & $\begin{array}{l}\text { Putri selalu } \\
\text { mendapatkan } \\
\text { dukungan } \\
\text { dan bantuan }\end{array}$ \\
\hline 14 & $\begin{array}{l}\text { Datuk } \\
\text { Agung } \\
\text { menceraika } \\
\mathrm{n} \text { istrinya } \\
\end{array}$ & $\begin{array}{l}\text { Aib keluarga } \\
\text { raja }\end{array}$ \\
\hline 23 & $\begin{array}{l}\text { Putri } \\
\text { Bungsu } \\
\text { kehilangan } \\
\text { orang } \\
\text { tersayang } \\
\end{array}$ & $\begin{array}{l}\text { Putri bungsu } \\
\text { menjadi janda }\end{array}$ \\
\hline 27 & $\begin{array}{l}\text { Tuan Raja } \\
\text { tidak } \\
\text { menemukan } \\
\text { perempuan } \\
\text { melebihi } \\
\text { Putri } \\
\text { Bungsu }\end{array}$ & $\begin{array}{l}\text { Raja tidak bisa } \\
\text { berpisah } \\
\text { dengan } \\
\text { istrinya }\end{array}$ \\
\hline 35 & $\begin{array}{l}\text { Putri } \\
\text { Bungsu } \\
\text { menunjukka } \\
\mathrm{n} \text { jalan ke } \\
\text { rumah }\end{array}$ & $\begin{array}{l}\text { Raja masih } \\
\text { diterima }\end{array}$ \\
\hline 52 & $\begin{array}{l}\text { Paman } \\
\text { bungsu } \\
\text { tidak ikut } \\
\text { serta dalam } \\
\text { keputusan }\end{array}$ & $\begin{array}{l}\text { Paman } \\
\text { melepas } \\
\text { tanggung } \\
\text { jawab }\end{array}$ \\
\hline
\end{tabular}




\begin{tabular}{|c|c|c|c|}
\hline & & itu & \\
\hline & 53 & $\begin{array}{l}\text { Paman } \\
\text { tertua } \\
\text { melempar } \\
\text { Putri } \\
\text { Bungsu ke } \\
\text { tengah } \\
\text { rumah } \\
\end{array}$ & $\begin{array}{l}\text { Putri Bungsu } \\
\text { mulai } \\
\text { disingkirkan }\end{array}$ \\
\hline & 54 & $\begin{array}{l}\text { Putri } \\
\text { Bungsu } \\
\text { dibuang } \\
\text { dalam } \\
\text { rimba }\end{array}$ & $\begin{array}{l}\text { Putri Bungsu } \\
\text { terusir dari } \\
\text { kampung }\end{array}$ \\
\hline & 56 & $\begin{array}{l}\text { Kerbau } \\
\text { mengantark } \\
\text { an Putri } \\
\text { Bungsu }\end{array}$ & $\begin{array}{l}\text { Kekuasaan } \\
\text { yang } \\
\text { ditinggalkan } \\
\text { oleh orang } \\
\text { tuanya }\end{array}$ \\
\hline & 61 & $\begin{array}{l}\text { Harta orang } \\
\text { tua Putri } \\
\text { Bungsu } \\
\text { dijual } \\
\text { pamannya }\end{array}$ & $\begin{array}{l}\text { Ketamakan } \\
\text { paman }\end{array}$ \\
\hline \multirow{6}{*}{$\begin{array}{l}\text { Simbol } \\
\text { ik }\end{array}$} & 11 & $\begin{array}{l}\text { Datuk } \\
\text { Agung dan } \\
\text { istrinya } \\
\text { belum } \\
\text { memiliki } \\
\text { anak }\end{array}$ & $\begin{array}{l}\text { Permasalahan } \\
\text { dalam } \\
\text { keluarga raja }\end{array}$ \\
\hline & 14 & $\begin{array}{l}\text { Datuk } \\
\text { Agung } \\
\text { menceraika } \\
\mathrm{n} \text { istrinya }\end{array}$ & $\begin{array}{l}\text { Aib pada } \\
\text { masa lalu }\end{array}$ \\
\hline & 32 & $\begin{array}{l}\text { Datuk } \\
\text { Agung } \\
\text { disuruh } \\
\text { kembali } \\
\text { pada Putri } \\
\text { Bungsu } \\
\text { dalam } \\
\text { mimpi } \\
\end{array}$ & $\begin{array}{l}\text { Raja } \\
\text { memperbaiki } \\
\text { hubungan }\end{array}$ \\
\hline & 38 & $\begin{array}{l}\text { Tabuh besar } \\
\text { dibunyikan }\end{array}$ & $\begin{array}{l}\text { Raja dan Putri } \\
\text { Bungsu } \\
\text { kembali rujuk }\end{array}$ \\
\hline & 51 & $\begin{array}{l}\text { Putri } \\
\text { Bungsu } \\
\text { dianggap } \\
\text { sebagai } \\
\text { orang celaka } \\
\end{array}$ & $\begin{array}{l}\text { Alasan untuk } \\
\text { mengusir } \\
\text { Putri Bungsu }\end{array}$ \\
\hline & 52 & $\begin{array}{l}\text { Paman } \\
\text { bungsu } \\
\text { tidak ikut } \\
\text { serta dalam }\end{array}$ & $\begin{array}{l}\text { Salah seorang } \\
\text { paman } \\
\text { melepas } \\
\text { tanggung }\end{array}$ \\
\hline
\end{tabular}

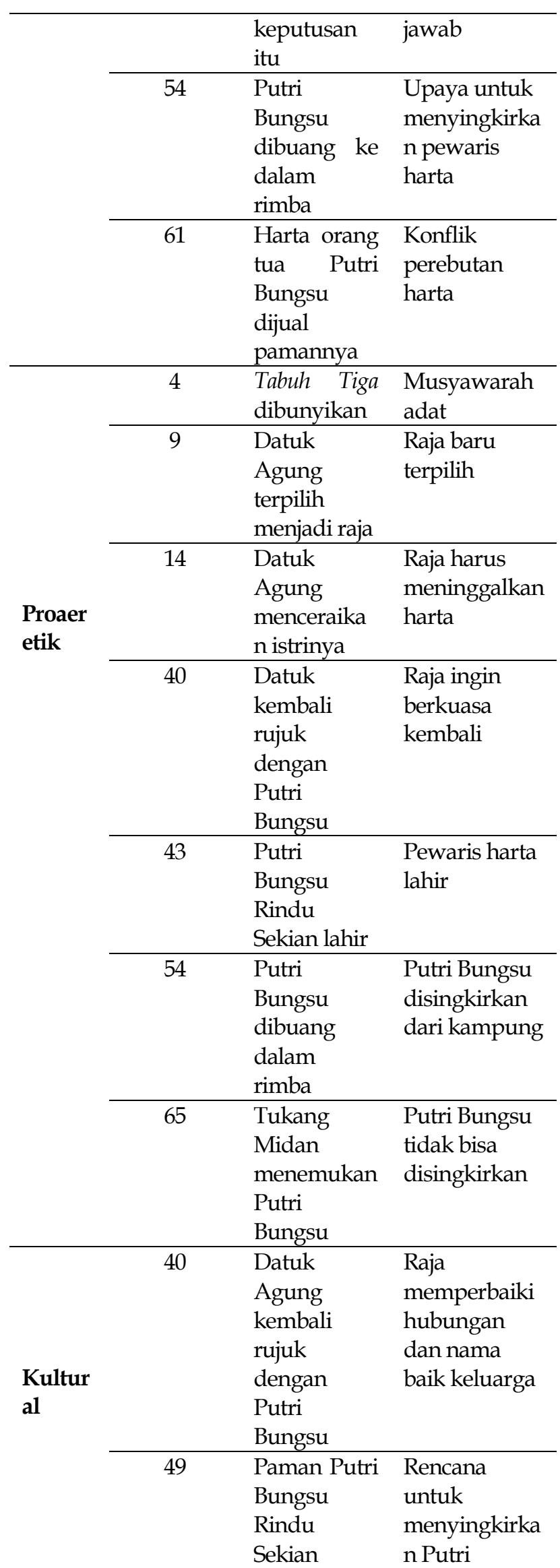




\begin{tabular}{cll}
\hline & berunding & Bungsu \\
\cline { 2 - 3 } 51 & Putri & Upaya \\
& Bungsu & menyingkirka \\
& dianggap & n pewaris \\
& sebagai & harta dan \\
& orang celaka & kekuasaan \\
\hline
\end{tabular}

Selain klasifikasi dan analisis leksia beserta kode yang menyertainya pada kunang Putri Bungsu Rindu Sekian, pada tabel 2 di bawah ini menunjukkan leksia dan kode yang terdapat pada kunaung Si Kamba Paya.

\section{Tabel 2}

\begin{tabular}{|c|c|c|c|}
\hline \multicolumn{4}{|c|}{ Kode dalam kunaung Si Kamba Paya } \\
\hline Kode & $\begin{array}{c}\text { No. } \\
\text { Leksia }\end{array}$ & Leksia & Makna \\
\hline \multirow{9}{*}{$\begin{array}{l}\text { Herme } \\
\text { neutik }\end{array}$} & 1 & $\begin{array}{l}\text { Seorang raja di } \\
\text { sebuah negeri }\end{array}$ & $\begin{array}{l}\text { Raja yang } \\
\text { berkuasa }\end{array}$ \\
\hline & 4 & $\begin{array}{l}\text { Anaknya } \\
\text { bermain bunga } \\
\text { yang } \\
\text { terkembang }\end{array}$ & $\begin{array}{l}\text { Harta yang } \\
\text { dimiliki Putri }\end{array}$ \\
\hline & 6 & $\begin{array}{l}\text { Putri dikejar } \\
\text { sampai ke } \\
\text { dalam rimba }\end{array}$ & $\begin{array}{l}\text { Bibi marah } \\
\text { kepada Putri }\end{array}$ \\
\hline & 13 & $\begin{array}{l}\text { Putri mencari } \\
\text { bunga } \\
\text { kembang } \\
\text { payung }\end{array}$ & $\begin{array}{l}\text { Putri } \\
\text { berkelana }\end{array}$ \\
\hline & 23 & $\begin{array}{l}\text { Putri disuruh } \\
\text { untuk singgah }\end{array}$ & Permintaan \\
\hline & 29 & $\begin{array}{l}\text { Nenek } \\
\text { menunjukkan } \\
\text { letak bunga } \\
\text { kembang } \\
\text { payung }\end{array}$ & $\begin{array}{l}\text { Penawaran } \\
\text { oleh nenek } \\
\text { tak dikenal }\end{array}$ \\
\hline & 31 & $\begin{array}{l}\text { Putri harus } \\
\text { menikah } \\
\text { dengan cucu } \\
\text { nenek tersebut } \\
\text { untuk } \\
\text { mendapatkan } \\
\text { bunga. }\end{array}$ & $\begin{array}{l}\text { Kesepakatan } \\
\text { yang harus } \\
\text { dipenuhi }\end{array}$ \\
\hline & 42 & $\begin{array}{l}\text { Putri } \\
\text { menyuruh } \\
\text { memandikan } \\
\text { orang tuanya }\end{array}$ & $\begin{array}{l}\text { Putri } \\
\text { memiliki } \\
\text { kuasa }\end{array}$ \\
\hline & 44 & $\begin{array}{l}\text { Putri } \\
\text { menunjukkan } \\
\text { bunga }\end{array}$ & $\begin{array}{l}\text { Putri } \\
\text { menunjukkan } \\
\text { kekuasaan }\end{array}$ \\
\hline
\end{tabular}

\begin{tabular}{|c|c|c|c|}
\hline & & $\begin{array}{l}\text { kembang } \\
\text { payung }\end{array}$ & yang ia miliki \\
\hline \multirow{5}{*}{ Semik } & 7 & $\begin{array}{l}\text { Putri diusir } \\
\text { oleh bibinya }\end{array}$ & $\begin{array}{l}\text { Putri } \\
\text { disingkirkan } \\
\text { dari kampung }\end{array}$ \\
\hline & 19 & $\begin{array}{l}\text { Putri berdoa } \\
\text { meminta } \\
\text { petunjuk }\end{array}$ & $\begin{array}{l}\text { Putri } \\
\text { memerlukan } \\
\text { bantuan }\end{array}$ \\
\hline & 22 & $\begin{array}{l}\text { Putri } \\
\text { menanyakan } \\
\text { orang rumah }\end{array}$ & $\begin{array}{l}\text { Putri } \\
\text { meminta } \\
\text { tolong }\end{array}$ \\
\hline & 27 & $\begin{array}{l}\text { Putri dijanjikan } \\
\text { bunga } \\
\text { kembang } \\
\text { payung }\end{array}$ & $\begin{array}{l}\text { Putri } \\
\text { mendapatkan } \\
\text { tawaran }\end{array}$ \\
\hline & 31 & $\begin{array}{l}\text { Putri harus } \\
\text { menikah } \\
\text { dengan cucu } \\
\text { nenek tersebut } \\
\text { untuk } \\
\text { mendapatkan } \\
\text { bunga }\end{array}$ & $\begin{array}{l}\text { Putri harus } \\
\text { memenuhi } \\
\text { keinginan } \\
\text { nenek }\end{array}$ \\
\hline \multirow{7}{*}{$\begin{array}{l}\text { Simbol } \\
\text { ik }\end{array}$} & 3 & $\begin{array}{l}\text { Raja } \\
\text { menitipkan } \\
\text { anaknya karena } \\
\text { pergi mencari } \\
\text { kayu }\end{array}$ & $\begin{array}{l}\text { Raja } \\
\text { kehilangan } \\
\text { kekuasaan } \\
\text { dan wibawa }\end{array}$ \\
\hline & 9 & $\begin{array}{l}\text { Raja } \\
\text { memerintahkan } \\
\text { mencari } \\
\text { anaknya }\end{array}$ & $\begin{array}{l}\text { Kekuasaan } \\
\text { yang masih } \\
\text { tersisa }\end{array}$ \\
\hline & 10 & $\begin{array}{l}\text { Raja tidak lagi } \\
\text { memerintah } \\
\text { karena sedih } \\
\text { kehilangan } \\
\text { putri mereka }\end{array}$ & $\begin{array}{l}\text { Raja kecewa } \\
\text { karena hilang } \\
\text { kuasa, } \\
\text { wibawa, serta } \\
\text { anak }\end{array}$ \\
\hline & 33 & $\begin{array}{l}\text { Putri } \\
\text { mendapatkan } \\
\text { bunga } \\
\text { kembang } \\
\text { payung }\end{array}$ & $\begin{array}{l}\text { Putri } \\
\text { mendapatkan } \\
\text { kekuasaan di } \\
\text { luar kampung }\end{array}$ \\
\hline & 34 & $\begin{array}{l}\text { Putri ingin } \\
\text { pulang } \\
\text { menjenguk } \\
\text { ayahnya }\end{array}$ & $\begin{array}{l}\text { Putri ingin } \\
\text { mengambil } \\
\text { alih } \\
\text { kekuasaan } \\
\text { yang ada di } \\
\text { kampung }\end{array}$ \\
\hline & 39 & $\begin{array}{l}\text { Orang terpukau } \\
\text { melihat } \\
\text { kedatagan putri } \\
\text { raja }\end{array}$ & $\begin{array}{l}\text { Putri tampak } \\
\text { siap untuk } \\
\text { berkuasa }\end{array}$ \\
\hline & 3 & $\begin{array}{l}\text { Raja } \\
\text { menitipkan }\end{array}$ & $\begin{array}{l}\text { Tindakan raja } \\
\text { karena tidak }\end{array}$ \\
\hline
\end{tabular}




\begin{tabular}{|c|c|c|c|}
\hline \multirow[t]{7}{*}{$\begin{array}{l}\text { Proaer } \\
\text { etik }\end{array}$} & & $\begin{array}{l}\text { anaknya karena } \\
\text { pergi mencari } \\
\text { kayu }\end{array}$ & $\begin{array}{l}\text { harus } \\
\text { memenuhi } \\
\text { kebutuhan } \\
\text { hidup secara } \\
\text { mandiri }\end{array}$ \\
\hline & 7 & $\begin{array}{l}\text { Putri diusir } \\
\text { oleh bibinya }\end{array}$ & $\begin{array}{l}\text { Putri } \\
\text { disingkirkan }\end{array}$ \\
\hline & 17 & $\begin{array}{l}\text { Putri mencari } \\
\text { bunga } \\
\text { kembang } \\
\text { payung }\end{array}$ & $\begin{array}{l}\text { Putri mencari } \\
\text { cara untuk } \\
\text { merebut } \\
\text { kekuasaan di } \\
\text { kampung }\end{array}$ \\
\hline & 26 & $\begin{array}{l}\text { Putri menetap } \\
\text { di rumah nenek } \\
\text { di atas bukit }\end{array}$ & $\begin{array}{l}\text { Putri belajar } \\
\text { untuk } \\
\text { mengasah } \\
\text { kemampuan }\end{array}$ \\
\hline & 31 & $\begin{array}{l}\text { Putri harus } \\
\text { menikah } \\
\text { dengan cucu } \\
\text { nenek tersebut } \\
\text { untuk } \\
\text { mendapatkan } \\
\text { bunga. }\end{array}$ & $\begin{array}{l}\text { Komitmen } \\
\text { yang harus } \\
\text { disanggupi } \\
\text { oleh putri }\end{array}$ \\
\hline & 32 & $\begin{array}{l}\text { Putri dan } \\
\text { suaminya } \\
\text { disuruh pulang }\end{array}$ & $\begin{array}{l}\text { Putri } \\
\text { dipersilahkan } \\
\text { untuk } \\
\text { kembali }\end{array}$ \\
\hline & 41 & $\begin{array}{l}\text { Putri sampai di } \\
\text { rumah }\end{array}$ & $\begin{array}{l}\text { Putri kembali } \\
\text { untuk } \\
\text { memerintah }\end{array}$ \\
\hline $\begin{array}{l}\text { Kultur } \\
\text { al }\end{array}$ & 43 & $\begin{array}{l}\text { Orang berpesta } \\
\text { membunuh } \\
\text { kerbau }\end{array}$ & $\begin{array}{l}\text { Perayaan atas } \\
\text { datangnya } \\
\text { pemimpin } \\
\text { baru }\end{array}$ \\
\hline
\end{tabular}

\subsection{Pembahasan}

Empat puluh leksia yang terdapat pada tabel 1 secara konotatif bercerita mengenai peristiwa yang pernah terjadi pada masa lalu tentang konflik internal dalam keluarga kerajaan. Raja yang bernama Datuk Agung merupakan pemimpin yang memiliki wibawa dan kekuasaan yang sangat luas. Oleh sebab itu, ia menginginkan pewaris harta dan kekuasaan yang ia miliki. Namun, iatidak kunjung memiliki keturunan. Datuk Agung menceraikan istrinya, lalu ingin mencari pengganti Putri Bungsu. Raja meninggalkan rumah tanpa membawa apapun. Hal ini mengandung makna bahwa yang memiliki kuasa atas harta di Kerinci ialah perempuan. Laki-laki hanya berperan sebagai orang yang mengelola dan menjaga harta dan kekuasaan, seperti yang terdapat pada kode hermeneutik pada leksia 22, raja pergi membuang diri, yang bermakna raja pergi tanpa membawa apapun.

Setelah mencari ke tempat-tempat yang jauh, Datuk Agung tidak menemukan satupun perempuan yang dapat menandingi kecantikan dan keelokan budi yang dimiliki oleh Putri Bungsu. Hal itu pula yang menyebabkan ia kembali rujuk dengan Putri Bungsu.

Pada akhirnya mereka memiliki anak yang dinamai seperti ibunya, Putri Bungsu, tetapi mereka justru meninggal dunia setelah kelahiran anak tersebut.Anak inilah yang menjadi pewaris atas harta dan kekuasaan yang ditinggalkan oleh orang tuanya. Namun, paman dari ibunya ingin menguasai harta yang dimiliki olehnya. Putri Bungsu pun disingkirkan dari kampungnya sendiri, seperti yang terdapat pada leksia 54, yaitu Putri Bungsu dibuang ke dalam rimba yang merupakan kode simbolik untuk menyingkirkan pewaris sko tinggi atau harta pusaka yang dimiliki oleh keluarga raja. Hal ini disebabkan Putri merupakan anak perempuan dari saudara perempuan pamanpamannya.

Hal itu menunjukkan bahwa masyarakat Kerinci yang menganut sistem kekerabatan matrilineal mewariskan harta kepada anak perempuan. Laki-laki hanya berperan untuk mengelola harta. Namun, pada kunaung ini, karena ketamakan pamannya, Putri Bungsu justru terusir agar pamannya dapat mengambil harta tersebut. Apabila putri tidak diketahui keberadaannya maka orang yang berhak berkuasa adalah pamannya yang tertua, yaitu saudara ibu kandungnya sendiri. Dengan demikian,tidak ada alasan anggota keluarga yang lain untuk menggugat paman tertua tersebut. 
Tabel 2 menunjukkan peristiwa yang terdapat pada kunaung Si Kamba Paya. Secara konotatif kunaung ini mengandung makna mengenai terusirnya putri raja yang disebabkan karena ayahnya tidak memiliki kekuasaan dan wibawa yang kuat di tengah masyarakat. Hal ini diperkuat oleh leksia 3 yang berbunyi raja menitipkan anaknya karena pergi mencari kayu; mengandung makna bahwa raja telah kehilangan kekuasaan, harta, dan wibawa di tengah masyarakat. Ia harus memenuhi kebutuhan hidupnya sendiri. Di samping itu, hal ini juga merupakan bentuk penegasan bahwa seorang pemimpin di Kerinci merupakan simbol. Ia adalah orang yang mengurusi persoalan administratif saja, sedangkan urusan harta dan dapur, raja bertanggung jawab secara mandiri.

Putri diusir oleh bibinya sendiri, seperti yang terdapat pada leksia 7. Hal ini menunjukkan bahwa telah terjadi konflik internal dalam keluarga raja. Hal ini disebabkan putri merupakan anak perempuan pertama dari keluarga raja. Dengan demikian, dia adalah orang yang akan mewarisi sko tinggi; harta pusaka warisan yang ada pada keluarga. Dialah orang yang memiliki jatah harta paling banyak. Untuk itu, ia harus disingkirkan dengan alasan putri memiliki mainan yang lebih bagus dibandingkan dengan mainan yang dimiliki oleh sepupunya, yaitu anak bibinya tersebut. Apabila putri tersebut tidak diketahui keberadaannya atau meninggal, anak perempuan yang akan mewarisi pusaka tinggi adalah sepupunya, anak dari bibinya itu.

Sehubungan dengan itu, Putri mencari bunga kembang payung, seperti yang ditunjukkan leksia 13, yaitu upaya dirinya untuk memiliki kemampuan dan kekuasaan agar bisa kembali ke kampung untuk merebut kekuasaan dan harta yang ia miliki dari keluarga bibinya. Hal tersebut terdapat pada leksia 33 kode simbolik, Putri mendapatkan bunga kembang payung; mengandung makna simbolik bahwa putri telah memiliki kemampuan untuk merebut hakhak yang ia miliki di kampung.

Analisis leksia dan lima kode yang terdapat pada kedua kunaung menunjukkan adanya benang merah pada kedua kunaung ini. Benang merah ituialah kesamaan peristiwa yang terdapat dalam cerita, yaitu terusir. Persoalan terusir menampilkan fakta sastra yang terjadi pada masa lalu bahwa terjadinya konflik internal dalam keluarga kerajaan untuk menguasai harta dan kekuasaan dari pemilik atau pun pewaris yang sah. Oleh sebab itu, pewaris tersebut harus disingkirkan dari dalam kampung. Dengan demikian, proses perebutan harta akan berjalan dengan mulus tanpa gangguan. Akan tetapi, kedua teks kunaung menunjukkan bahwa pewaris yang sah akan tetap menjadi pemenang dari perseteruan tersebut. Meskipun tidak dapat menguasai harta dan kekuasaan, mereka menang dalam pikiran masyarakat. Hal ini ditunjukkan oleh leksia 43 pada kunaung Si Kamba Paya,yaitu Orang berpesta membunuh kerbau sebagai perayaan atas datangnya pemimpin baru yang sah; atau pada leksia 65 pada kunaung Putri Bungsu Rindu Sekian yaitu Tukang Midan menemukan Putri Bungsu yang mengandung makna bahwa pewaris yang sah tidak dapat disingkirkan.

\subsubsection{Relevansi Kunaung Putri BungsuRindu Sekian dan Kunaung Si Kamba Paya dengan Masyarakat Kerinci}

Persoalan terusir dalam kedua kunaung Kerinci ini disebabkan oleh konflik internal dalam keluarga. Konflik ini timbul karena memperebutkan harta dan kekuasaan.Oleh karena itu, keluar dari kampung adalah solusi untuk mendamaikan keadaan. Orangorang yang terusir pun memiliki kesempatan untuk membekali diri dengan mengum- 
pulkan harta atau menambah pengetahuan supaya dapat kembali ke kampung dan kembali berkuasa sesuai dengan aturan adat yang berlaku.

Kedua teks kunaung merupakan kode simbolik tentang fakta sastra pada masa lalu di Kerinci mengenai tragedi yang pernah terjadi di tengah masyarakat.Tragedi tersebut ialah konflik yang terjadi dalam keluarga kerajaan pada masa lalu. Konflik ini relevan dengan apa yang terjadi pada hari ini di Kerinci, yaitu kerap ada konflik antarsatu keluarga dengan keluarga yang lain. Konflik tersebut seperti yang terdapat dalam kedua kunaung ini. Konflik yang terjadi dalam kunaung Putri Bungsu Rindu Sekian antara putri dengan pamannya. Putri dianggap sebagai anak yang membawa celaka dan dibuang oleh pamannya dari dalam kampung. Kunaung Si Kamba Paya menunjukkan jika masyarakat Kerinci kerap berkonflik antara satu dengan yang lain pada masa lalu. Marsden (2012) mengatakan bahwa pada saat ia memasuki wilayah Kerinci, orang-orang Kerinci penuh curiga terhadap orang baru maupun sesamanya. Orang Kerinci juga selalu dalam keadaan siaga untuk berperang dengan desa yang lain. Hal ini menunjukkan bahwa pada masa lalu masyarakat Kerinci memang telah berkonflik antarsesamanya.

Konflik perebutan kekuasaan dalam internal masyarakat Kerinci dikarenakan Kerinci yang menjadi ladang emas pada periode 1770-an. Andaya (1993: 166) menyebutkan bahwa Kerinci menjadi perebutan dua kerajaan besar yang berada di Minangkabau dan di Jambi. Hal itu disebabkan karena Kerinci adalah daerah penghasil emas. Penguasa yang ada di Jambi atau pun di Minangkabau membujuk pemimpin di Kerinci agar mau berkongsi agar bisa mendapatkan pasokan emas.

Hal inilah yang memicu konflik dalam keluarga.Konflik tersebut disebabkan adanya anggota keluarga yang memiliki kedudukan adat lebih tinggi menggunakan kekuasaannya untuk mengambil atau pun menambang emas tanpa seizin pemilik atau pun pewaris yang sah.

Akibatnya, timbul konflik perang saudara di Kerinci.Konflik yang terjadi pada umumnya antara paman dengan keponakan. Konflik tersebut terkait erat dengan keinginan untuk menguasai sawah, ladang, atau pun tanah terutama daerah yang memiliki kandungan emas.

Keleluasaan untuk mengambil untung secara pribadi disebabkan orang yang memiliki kekuasaan secara adat adalah paman, sedangkan orang yang memiliki lahan adalah perempuan. Kerinci adalah wilayah yang menganut sistem matrilineal sehingga pewaris harta diberikan kepada perempuan (Watson, 2020: 7). Harta pusaka terbagi atas dua, yaitu harta berat dan harta ringan.Harta ringan adalah harta yang dibagikan kepada saudara laki-laki, seperti ternak, padi, uang, dan sebagainya. Sementara itu, harta berat adalah sawah, tanah, dan rumah (Umar, 2008: 171). Semua harta pusaka diwariskan kepada perempuan, sementara itu laki-laki hanya berhak untuk mengelola serta mewarisi gelar adat. Oleh sebab itu, perempuan-perempuan yang mewarisi pusaka dalam kunaung ini berusaha untuk disingkirkan oleh orang yang akan merebut warisan tersebut.

\subsubsection{Ideologi yang Dibungkam}

Kunaung merupakan gambaran peristiwa kelam pada masa lalu. Oleh sebab itu, kunaung Putri Bungsu Rindu Sekian dan kunaung Si Kamba Paya berperan sebagai alat untuk memediasi peristiwa kelam pada masa lalu itu dengan kehidupan masa mendatang pada masyarakat Kerinci.

Kunaung Putri Bungsu Rindu Sekian dan kunaung Si Kamba Paya merupakan tirai nalar untuk menutupi tragedi yang pernah terjadi 
pada masa lalu. Tirai nalar ialah upaya menutupi hal-hal yang terlihat kontradiktif dengan cara mendesain simbol-simbol sedemikian rupa hingga tampak rapi serta tidak menimbulkan tanda tanya bagi logika manusia, seperti yang ada pada kedua kunaung ini. Dengan demikian, kedua kunaung ini telah menjadi pengobat luka kolektif atas peristiwa kelam pada masa lalu bagi masyarakat Kerinci.Dengan demikian, kunaung juga berperan untuk membungkam tragedimasa lalu agar tidak menjadi ingatan kolektif bagi generasi mendatang.

Kunaung menjadi angan-angan kolektif masa depan agar masyarakat Kerinci dapat hidup secara harmonis dan tidak berbenturan satu sama lain. Inilah yang didengung-dengungkan dalam kunaung agar tidak ada lagi konflik-konflik serupa yang terjadi di tengah masyarakat Kerinci. Cita-cita keharmonisan adalah impian nenek moyang orang Kerinci. Kunaung menjadi jalan untuk menyuarakan cita-cita tersebut.

\section{Simpulan}

Analisis semiologi terhadap kunaung Putri Bungsu Rindu Sekian dan Kunaung Si Kamba Paya melalui peristiwa terusir menunjukkan bahwa kunaung menjadi kode simbolik, yaitu sebagai tirai nalar untuk membungkam tragedi kolektif masa lalu supaya tidak menjadi luka kolektif dalam masyarakat Kerinci. Hal itu merupakan upaya nenek moyang orang Kerinci supaya kunaung menjadi media untuk menyuarakan perdamaian. Kunaung menjadi angan-angan kolektif nenek moyang orang Kerinci agar masyarakat Kerinci memiliki kehidupan harmonis di masa depan. Kunaung telah berperan sebagai alat untuk menyuarakan cita-cita tersebut. Makna inilah yang tersembunyi di balik persoalan terusir yang terdapat dalam teks-teks kunaung.

\section{Daftar Pustaka}

Andaya, Barbara Watson. 1993. To Live as Brothers: Southeast Sumatra in the Seventeenth and Eighteenth Centuries. Honolulu: University of Hawaii Press.

Barthes, Roland. 1974. S/Z. New York: Hill and Wang.

Barthes, Roland. 1983. Mytologies. New York: Hill and Wang.

Efrison. 2017. "Analisis Cerita Tupai Janjang: Teori Fungsi William R. Bascom." Ceudah 7(1):1-11.

Jaya, S. 2019. "The Value of Religious Education in Kerinci Kunun Text." KnE Social Sciences 3(15):77. https:/ / doi.org/10.18502/kss.v3i15.4356

Kalelioğlu dan Günay. 2018. "Analysis of Duha Koca Oglu Deli Dumrul Narrative Within The Framework of Literary Semiotics." Turkish Studies 13:229-56. https:/ / doi.org/10.7827/TurkishStudies .12890

Karimi, A. Latief. 1968. Penyelidikan Tentang Kesusastraan Kerinci Dan Manfaat Bagi Pembinaan Kebudayaan Indonesia (Tesis). Padang: FKSS IKIP Padang.

Kurniawan. 2001. Semiologi Roland Barthes. 1st ed. Magelang: Indonesiatera.

Maiza, Suci. 2020. “Autonomy of Kerinci'S Kunun Toward Character Education in Primary Schools in Sungai Penuh City (Otonomi Kunun Kerinci Terhadap Pendidikan Karakter Di Sekolah Dasar Di Kota Sungai Penuh)." Gramatika STKIP PGRI Sumatera Barat 6(1):105-17. https:/ / doi.org/10.22202/jg.2020.v6i1.3 619 
Marsden, William. 2012. The History of Sumatra: Containing an Account of the Government, Laws, Customs, and Manners of the Native Inhabitants. New York: Camridge University Press.

Nazurty. 2016. "Semiotic Review of Verbal Literature of Riwok Kerinci." Ijlecr International Journal of Language Education and Culture Review 2(1):64-73. https:/ / doi.org/10.21009/IJLECR.021.1 7

Piliang, Yasraf Amir. 2019. Semiotika Dan Hipersemiotika: Kode, Gaya, Dan Matinya Makna. Yogyakarta: Cantrik Pustaka.

Rosa, Silvia. 2015. Ideologi Berkabut: Gelar Adat Dan Mitos Masyarakat Minangkabau. 1st ed. Padang: Lembaga Pengembangan Teknologi dan Informasi dan Komunikasi (LPTIK) Universitas Andalas. https://doi.org/10.22146/jh.43880

Rosa, Silvia. 2019. "Deceptive Strategies in Literature: The Meaning of Folded Story." 31(3).

Udin, Syamsudin. 1983. Struktur Sastra Lisan Kerinci. Jakarta: Pusat Pembinaan dan Pengembangan Bahasa Departemen Pendidikan dan Kebudayaan.

Umar, Bakhtiar. 2008. Hukum Pusaka Adat Kerinci Dari Perspektif Hukum Pusaka Islam (Disertasi). Kuala Lumpur: University Malaya.

Watson, C. W. 2020. "Local Lineages in Kerinci , Sumatra." Indonesia and the Malay World 0(142):1-18. https:/ / doi.org/10.1080/13639811.2020. 1801030 